\title{
STRATEGI PUBLIC RELATIONS DALAM MENJAGA CORPORATE IMAGE DI PT PERTAMINA (PERSERO) MARKETING OPERATION REGION (MOR) III
}

\section{IMAGE IN PT PERTAMINA (PERSERO) MARKETING OPERATION REGION (MOR) III}

\author{
Hakanna1a, IA Ratnamulyani² $^{2}$, AA Kusumadinata ${ }^{3}$ \\ ${ }^{123}$ Ps. Ilmu Komunikasi, Fakultas Ilmu Sosial Dan Ilmu Politik, Universitas Djuanda Bogor \\ Jl. Tol No 1 Kotak Pos 35 Bogor 16740 \\ “Korespondensi: Hakana, Email: hakanna@unida.ac.id \\ (Diterima: 03-04-2018; Ditelaah: 14-04-2018 ; Disetujui: 20-04-2018)
}

\begin{abstract}
The rapid development of business to make the existing strategy will not always be relavan continue to facing increasingly complex business challenges. The existence of public relations is very important in an organization where the important factors of the existence of public relations as a messenger from the company to the public as expressed. Public Relations for communication communications are conducted correctly and continuously with good intentions within the framework covered by a company with internal public and external company, and that public relations also help in order to achieve specific goals based on mutual understanding. The purpose of the research was to explain the strategy of Public Relations in Pertamina marketing operation region III in maintaining corporate image. This research used qualitative method. The result of the research was how the public relations strategy in maintaining corporate image in pertamina marketing operation region III which was done in communication communication unit that was with monitoring media, keeping good company, maintaining good relationship with MUSPIDA.
\end{abstract}

Keywords : corporate image, public opinion, socialization

\begin{abstract}
ABSTRAK
Perkembangan bisnis yang begitu pesat membuat strategi yang ada tidak selalu akan relavan terus mengahadapi tantangan bisnis yang semakin kompleks. Keberadaan humas sangat penting dalam sebuah organisasi dimana faktor-faktor penting dari keberadaan humas sebagai penyampai pesan dari perusahaan kepada masyarakat seperti yang diungkapkan. Public Relations suatu upaya komunikasi yang dilakukan secara terencana dan berkesinambungan dengan niat baik dalam rangka terciptanya suatu pengertian antara suatu perusahaan dengan public internal dan ekternal perusahaan,dan bahwa public relations juga suatu upaya dalam rangka mencapai tujuan-tujuan spesifik yang berlandaskan pada saling pengertian. Adapun tujuan penelitian adalah menjelaskan strategi public relations di Pertamina marketing operation region III dalam menjaga corporate image. Penelitian ini mengunakan metoda kualitatif. Hasil penelitian yang dihasilkan yaitu bagaimana strategi public relations dalam menjaga corporate image di pertamina marketing operation region III yang dilakukan di unit kerja communication relations yaitu dengan media monitoring, menjaga nama baik perusahaan, menjaga hubungan baik dengan MUSPIDA.
\end{abstract}

Kata kunci : corporate image, opini publik, sosialisasi.

Hakana, IA Ratnamulyani, AA Kusumadinata. 2018. Strategi Public Relations Dalam Menjaga Corporate Image Di Pt Pertamina (Persero) Marketing Operation Region (Mor) III. Jurnal Komunikatio 4 (2) : 63-70. 


\section{PENDAHULUAN}

Citra adalah kesan yang diperoleh seseorang berdasarkan pengetahuan dan pengertiannya tetang fakta-fakta atau kenyataan. Untuk mengetahui citra suatu perusahaan di mata masyarakat sebagai konsumen, instansi terkait, dan masyarakat di lingkungan perusahaan terbentuk dari dari pengetahuan dan informasi-informasi yang diterima dari perusahaan tersebut.

Citra merupakan identitas perusahaan yang perlu dibentuk secara terencana dan berkesinambungan dengan tujuan yang spesifik.

Perkembangan dunia bisnis begitu pesat, tetapi tidak semua strategi akan relevan menghadapi tantangan dunia bisnis yang semakin kompleks. Dengan demikian Praktisi public relations dituntut untuk terus belajar dalam membaca situasi kondisi saat ini dan akan datang dan mampu merespons arus informasi yang tepat di era digital seiring dengan perkembangan teknologi. Public Relations adalah bagian penting dari suatu perusahaan karna menyangkut suatu interaksi dalam membina suatu hubungan baik. Setiap orang pada dasarnya juga selalu mengalami PR, kecuali ketika dia terisolasi dan tidak menjalin kontak dengan manusia lainya (Aldhily 2017).

Corporate image dianggap sebagai penilaian keseluruhan perusahaan di benak masyarakat (Aydin \& Ozer 2005). Public Relation berperan penting dalam membentuk corporate image yang positif dan tentunya ada strategi-strategi yang dilakukan sebagai suatu upaya dalam membentuk dan mempertahankan corporate image. Strategi Public Relations harus memiliki unsur-unsur yang didalamnya sudah terencana baik untuk jangka panjang dan jangka pendek dan menyusun rencana teknis secara spesifik. strategi yang dilakukan public relations pada dasarnya mengacu pada visi misi organisasi dan harus sejalan dengan strategi perusahaan, sehingga strategi yang dibuat harus terencana dan tersusun yang berhubungan dengan tujuan perusahaan. Tujuan penelitian ini adalah menjelaskan strategi komunikasi public relations di Pertamina marketing operation region III dalam menjaga corporate image.

\section{Kerangka Teoritis}

Citra itu sendiri digambarkan melalui persepsi-motivasi-sikap.Feedback nya dapat suatu penolakan atau penerimaan, positif dan negative. Kegiatan PR adalah kegiatan komunikasi. Kemampuan atau kecakapan komunikasi dapat membantu membangun hubungan dan memelihara hubungan tersebut. Pengertian hubungan merupakan sejumlah harapan yang dua orang miliki bagi perilaku mereka didasarkan pada pola interaksi antara mereka (Littlejhon 2017).

Hubungan yang baik ialah dimana interaksi-interaksi sifatnya memuaskan dan sehat bagi mereka yang terlibat interaksi tersebut.hubungan baik tidak terjadi begitu saja dan juga tidak tumbuh dan terpelihara begitu saja. Hubungan terjalin berawal dari sebuah komunikasi yang baik, maka dengan itu praktisi PR harus berkomunikasi dengan baik agar hubungan dapat berkesinambungan, dan berkembang juga berkesinambungan, beberapa perilaku kunci harus ada. Fajri (2017) menyatakan bahwa penting suatu lembaga memiliki loyalitas terhadap mitra sehingga mampu meningkatkan publisitas dilingkungan lembaga tersebut. Purwani (2009) menyebutkan bahwa citra yang baik dari suatu organisasi akan mempunyai dampak yang menguntungkan, sedangkan citra yang negatif akan merugikan perusahaan atau organisasi. Corporate image yang positif dapat meningkatkan dikenalnya nama perusahaan, membangun itikad baik bagi perusahaan serta produknya atau mengidentifikasi dirinya sendiri dengan beberapa aktivitas yang bisa diterima secara sosial dan bermakna. Corporate image merupakan persepsi tentang nama baik atau citra positif suatu perusahaan di mata konsumen / relasi bisnisnya, yang dapat diukur dari: (1) perusahaan dapat dipercaya, (2) perusahaan memiliki reputasi baik, (3) perusahaan dikenal secara luas atau memiliki nama besar, (4) perusahaan bekerja secara profesional, (5) perusahaan dapat memenuhi harapan pelanggan. Dengan adanya citra 
positif yang dimiliki oleh perusahaan / organisasi, maka membuat para pelanggan (penerbit) merasa mantap dan percaya melakukan kerjasama dengan pihak perusahaan / organisasi.

\section{METODE PENELITIAN}

Penelitian ini menggunakan metode deskriptif alasan digunakan metode ini karena metode deskriptif merupakan penelitian yang memiliki tujuan untuk mengumpulkan informasi aktual secara rinci mengenai suatu masalah yang ada sesuai dengan variabelvaribel yang diteliti. Oleh karena itu dalam metode ini, peneliti hanya mendiskripsikan informasi apa adanya sesuai dengan instrument yang diteliti dan tidak bertindak sebagai pengamat tanpa dibebani atau diarahkan oleh teori. Peneliti berusaha untuk mengumpulkan informasi atau data sebanyakbanyaknya yang berkenanaan dengan Strategi public relation Dalam Menjaga Corporate
Image di PT.PERTAMINA Marketing Operation Region III. Metode penelitian kualitatif berguna untuk pemahaman yang lebih mendalam tentang makna (arti subjektif dan penafsiran) dan konteks tingkah laku serta proses yang terjadi pada faktor-faktor yang berkaitan dengan tingkah laku tersebut (Afrizal 2016). Adapun Informan merupakan subyek penelitian untuk memperoleh data dari tujuan penelitian ini. Informan, adalah orang yang benar-benar tahu dan terlibat dalam subyek penelitian tersebut, yaitu subyek yang dapat membantu peneliti dengan cepat mendapatkan informasi. Informan pada penelitian ini:

Tabel 1. Daftar informan penelitian

\begin{tabular}{llrll}
\hline No & Nama & Usia & Kelompok informan & \multicolumn{1}{c}{ Jabatan } \\
\hline $\mathbf{1}$ & DHF & 38 Tahun & Informan Kunci & $\begin{array}{l}\text { Unit Manager } \\
\text { Communication dan } \\
\text { Tanggung Jawab Sosial } \\
\text { (TJS) }\end{array}$ \\
\hline $\mathbf{2}$ & N & 51Tahun & Informan Kunci & $\begin{array}{l}\text { Manager Fuel Retail } \\
\text { Marketing }\end{array}$ \\
\hline $\mathbf{3}$ & TDK & 37 Tahun & Informan Kunci & $\begin{array}{l}\text { Senior Region Fuel } \\
\text { Marketing }\end{array}$ \\
\hline $\mathbf{4}$ & LiD & 37 Tahun & Informan Insidentil & - \\
\hline $\mathbf{5}$ & Ae & 43 Tahun & Informan Insidentil & - \\
\hline
\end{tabular}

Langkah selanjutnya data dikumpulkan melalui wawancara mendalam. Wawancara tersebut peneliti lakukan dengan memperoleh informasi sebanyak mungkin berkenaan dengan strategi public relations untuk menjaga corporate image di PT. Pertamina Marketing Operation Region III dari tahun
2016 sd 2018. Setelah data terkumpul lalu data di olah dengan menggunakan kategorisasi dilanjutkan dengan mengelompokan hal - hal yang berkenaan dengan pertanyaan peneltian, dilanjutkan dengan penarikan kesimpulan dan verifikasi data. 


\section{HASIL DAN PEMBAHASAN}

\section{Kegiatan Public Relations dalam Menjaga Corporate Image Pertamina}

PT Pertamina (Persero) terbagi menjadi dua sektor, yaitu hulu dan hilir. Sektor hulu meliputi eksplorasi dan produksi minyak, gas, dan panas bumi. Sedangkan sektor hilir meliputi bisnis Pengolahan, Pemasaran \& Niaga, serta bisnis LNG. Bisnis Pemasaran \& Niaga mencakup aktivitas pendistribusian produk-produk hasil minyak dan petrokimia yang diproduksi oleh kilang Pertamina maupun yang diimpor, baik untuk tujuan pasar dalam negeri maupun luar negeri, serta didukung oleh sarana distribusi dan transportasi melalui darat dan laut. PT Pertamina (Persero) Marketing Operation Region III merupakan bagian dari sektor hilir dan pemasaran khususnya. Pertamina memiliki tata nilai sebagai komitmen perusahaan untuk mewujudkan visi dan misinya berdasarkan standar global dan penerapan tata kelola perusahaan yang baik (Good Corporate Governance). Nilai-nilai Pertamina disebut dengan 6C, terdiri dari Clean, Competitive, Confident, Customer Focus, Commercial dan Capable. Nilai-nilai ini wajib diketahui dan menjadi pedoman bagi seluruh karyawan dalam beraktivitas. Pertamina menetapkan enam tata nilai perusahaan yang dapat menjadi pedoman bagi seluruh karyawan dalam menjalankan aktivitas sehari-hari. Penerapan tata nilai $6 \mathrm{C}$ didasarkan pada Surat Keputusan Direktur Utama PT Pertamina (Persero) No.Kpts-022/ COOOOO/2013-S0 Tentang Penerapan Tata Nilai 6C 01 Pertamina dan Anak Perusahaan (Operation Holding).

Unit kerja humas di Pertamina MOR III bernama communication relations yang memiliki aktivitas rutin, yaitu media monitoring bertugas untuk memonitor beritaberita yang beredar secara on line, media cetak dan laporan di layanan konsumen. Informasi yang didapat dari media monitoring tersebut lalu masuk ke bagian team analisa dari informasi berita-berita yang didapat, dan untuk berita di teliti dari isi berita tersebut, apakah berita yang sudah beredar tersebut dengan konfirmasi pihak Pertamina communication relations Marketing Opration Region III atau tidak, jika telah di konfirmasi maka communicaton relations Pertamina Marketing Opration Region III tidak memerlukan lagi untuk mengkonfirmasi berita tersebut dan jika belum maka dari pihak communication relations Pertamina akan menghubungi pihak media untuk meminta klarifikasi dan memohon diterbitkan kembali hak jawab dengan press realease yang dikeluarkan oleh pertamina.

Penyelenggarakan event atau kegiatan khusus (special event) dalam humas merupakan salah satu kiat untuk menarik perhatian media pers dan public dalam menciptakan suatu hubungan baik antara suatu perusahaan dengan public ekternal,dan dalam event itu juga kegiatan promosi bisa dikemas guna memperkenalkan productproduct perusahaan dan hal itu dilakukan oleh unit communication relations dalam setiap event dalam bentuk sosialisasi edukasi, promosi dan Tanggung Jawab Sosial (TJS). Ruslan (2016) kegiatan special event dari humas/PR tersebut diharapkan mampu memuaskan pihak-pihak lain yang terlibat atau terkait untuk berperan serta dalam suatu kesempatan pada acara khusus humas, baik untuk meningkatkan (knowledge) pengetahuan, (awareness) kesadaran, maupun upaya pemenuhan selera (pleasure) dan menarik simpati dan empati, sehingga mampu menumbuhkan saling pengertian bagi kedua belah pihak dan pada akhirnya dapat menciptakan citra (image) positif dari masyarakat atau publik sebagai target sasaran. Purwani (2009) coorporate image yang positif dapat meningkatkan dikenalnya nama perusahaan, membangun niat baik bagi perusahaan serta produknya atau mengidentifikasikan dirinya sendiri dengan beberapa aktivitas yang bisa diterima secara sosial dan bermakna. Kegiatan tersebut hanya dilakukan sesekali tetapi harus berkesinambungan dan menyatakan public relations adalah keseluruhan upaya yang dilakukan secara terencana dan 
berkesinambungan dalam rangka menciptakan dan memelihara niat baik (goodwill) dan saling pengertian antara suatu organisasi dengan segenap khalayaknya. Hal itu dilakukan Pertamina MOR III melalui unit Communication Relations mengadakan berbagai event. Adapun kegiatan yang telah diselenggarakan oleh Pertamina MOR III sebagai teknis Public Realtions di unit communication relations Pertamina MOR III adalah sebagai berikut :

Tabel 2. Kegiatan publiv relations pertamina dalam menagkal isu

\begin{tabular}{|c|c|c|c|}
\hline Kegiatan PR & Tahun & Tujuan & Isu Pertamina \\
\hline $\begin{array}{l}\text { Pertamax Reading } \\
\text { Corner }\end{array}$ & 2018 & $\begin{array}{l}\text { Sebagai bantuan TJS } \\
\text { Pertamina kepada SMAN } 75 \\
\text { Jakarta }\end{array}$ & Pendidikan \\
\hline Safety Riding & 2018 & Sosialisasi edukasi & Keamanan berkendara \\
\hline $\begin{array}{l}\text { Fulltank Community } \\
\text { Festival }\end{array}$ & 2018 & Sosialisasi edukasi „Baksos & pendidikan \\
\hline $\begin{array}{l}\text { Tanggung Jawab } \\
\text { Sosial (TJS) }\end{array}$ & 2017 & $\begin{array}{l}\text { Pertamina beri santunan dan } \\
\text { baksos }\end{array}$ & Kemanusiaan \\
\hline $\begin{array}{l}\text { Tanggung Jawab } \\
\text { Sosial (TJS) }\end{array}$ & 2017 & $\begin{array}{l}\text { Membantu gempa bumi di } \\
\text { Tasikmalaya }\end{array}$ & Kemanusiaan \\
\hline $\begin{array}{l}\text { Tanggung Jawab } \\
\text { Sosial (TJS) }\end{array}$ & 2017 & $\begin{array}{l}\text { Kontribusi pada dunia } \\
\text { pendidikan untuk } \\
\text { masyarakat }\end{array}$ & Pendidikan \\
\hline $\begin{array}{l}\text { Turing Lamborghini } \\
\text { Bandung Run } 2017\end{array}$ & 2017 & $\begin{array}{l}\text { Agar menggunakann bahan } \\
\text { bakar product Pertamina }\end{array}$ & Energi \\
\hline $\begin{array}{l}\text { Pertamina manfaatkan } \\
\text { ciliwung untuk } \\
\text { sumber air minum }\end{array}$ & 2016 & Peduli lingkungan hidup & Lingkungan \\
\hline $\begin{array}{l}\text { Tanggung Jawab } \\
\text { Sosial (TJS) }\end{array}$ & 2016 & Membantu korban banjir & Kemanusiaan \\
\hline $\begin{array}{l}\text { Program TJS } \\
\text { Pertamina }\end{array}$ & 2016 & Untuk kesehatan gizi balita & Kesehatan \\
\hline Sosialisasi edukasi & 2016 & $\begin{array}{l}\text { Mendukung SMK } \\
\text { kembangkan wawasan }\end{array}$ & Pendidikan \\
\hline Sosialisasi edukasi & 2016 & $\begin{array}{l}\text { Pertamina peduli pelestarian } \\
\text { lingkungan }\end{array}$ & Lingkunagan \\
\hline Promosi & 2016 & $\begin{array}{l}\text { Agar menggunakann bahan } \\
\text { bakar product Pertamina }\end{array}$ & Eco energi \\
\hline Promosi & 2016 & $\begin{array}{l}\text { Untuk penggunaan product } \\
\text { oli Pertamina }\end{array}$ & Eco energi \\
\hline
\end{tabular}

Fungsi humas atau public relations adalah sebagai penyampai pesan dari perusahaan untuk membina hubungan baik antar lembaga (organisasi) dengan publiknya, internal maupun eksternal dalam rangka menanamkan pengertian iklim pendapat (opini public) yang menguntungkan kepada semua. Nova (2011) humas perlu melakukan perencanaan yang terarah. Anang (2014) keberadaan humas sangat penting dalam sebuah organisasi dimana faktor-faktor penting dari keberadaan humas itu yaitu: produk dan jasa instansi sangat perlu untuk diinformasikan (disosialisasikan) kepada masyarakat (prospek pelanggan), mengoordinir dan melaksanakan kegiatan pelayanan sebagai upaya untuk 
memberikan informasi mengenai produk dan membangun image instansi, membina hubungan baik secara internal maupun eksternal, menindak lanjuti keinginan dan kebutuhan pelanggan (konsumen) serta melayani keluhan-keluhan yang mungkin timbul, menangani penanganan secara khusus terhadap perselisihan yang mungkin timbul selama proses kegiatan perusahaan berjalan serta kepatuhan updating terhadap kelengkapan/keabsahan/legalitas dokumen perusahaan sesuai peraturan pemerintah.

Kegiatan atau Event adalah strategi public relations dalam Humas dalam Kegiatan atau Event adalah bertujuan menyampaikan pesan kepada masyarakat baik itu berupa kegiatan sosialisasi, edukasi dan TJS. Dalam membangun tujuan program PRs perlu melakukan (1) identifikasi khalayak penentu (key publics), (2) menetapkan kebijakan atau aturan untuk menentukan strategi yang akan dipilih, (3) memutuskan strategi yang digunakan. Unit Communication Relation marketing operation region III melakukan setiap kegiatan dengan penuh perencanaan dari mulai tema kegiatan yang mengacu pada isu yang sedang berkembang, target yang menjadi sasaran dan lokasi diadakan kegiatan tersebut, seperti kegiatan di bulan Maret 2018 yang diketahui peneliti pada saat peneliti mengambil data di Unit Communication Relation marketing operation region III bahwa Unit Communication
Relation marketing operation region III menggelar edukasi mengenai safety riding atau keselamatan berkendara, tema kegiatan itu diambil dari isu yang sedang berkembang bahwa seringnya terjadi kecelakaan kendaraan truck tanki pengangkut BBM (bahan bakar minyak), dengan itu pihak Unit Communication Relation marketing operation region III menghadirkan para pakar untuk berbagi tips supaya aman berkendara, juga memberikan pemberitahuan untuk hati-hati ketika melintas atau beriringan dengan mobil pengangkut BBM (bahan bakar minyak) tersebut, sasaran yang menjadi target yaitu siswa SMA yang menggunakan motor dan lokasi yang dipilih yaitu SMA yang berada di area sekitaran pengisian tanki BBM (bahan bakar minyak). Narasumber yang hadir adalah perwakilan dari korlantas Mabes POLRI, komunitas sepeda motor Nmax dan fungsi HSSE Pertamina.

Selain sosialisasi edukasi yang disampaikan, Pertamina juga menghadirkan beberapa produk Pertamina seperti Oli Enduro dan Bright gas di lokasi acara. Product pertamina itu dihadirkan untuk mensosilisasikan produk pertamina dan mengenal lebih dekat konsumen Pertamina. Kegiatan Event tersebut saling bersinergi dengan melibatkan pihak instansi, media diajak sebagai partner dan tujuan yang menjadi sasaran dikemas tidak hanya saat ini saja tetapi jangka panjang kedepan.

\section{Strategi Public Relations dalam Menjaga Corporate Image Pertamina}

Strategi public relations Pertamina menggunakan tiga pendekatan sesuai dengan fungsinya di unit kerja communication Relations. Adapun pendekatan tersebut antara lain : (1) Menjaga nama baik perusahaan dengan banyak membuat program-program positif berupa Tanggung Jawab Sosial (TJS) maupun promosi. Seperti kegiatan pada Tabel 2 yang dalam hal ini bertujuan menjaga nama baik perusahaan tidak terlepas dari suatu hubungan komunikasi yang terjalin harmonis dengan pihak media, konsumen dan lembaga terkait. Aldhily (2017) menyebutkan terdapat lima pendekatan untuk membina hubungan baik yaitu inisiasi (inititaion), sifat mau mendengarkan pengungkapan diri (self disclousure), dukungan emosional (emotional suport), pengelolaan konflik (conflict management).

Kriyantono (2014) Strategi pemulihan citra merupakan usaha menjaga nama baik perusahaan dengan memperbaiki citra dan reputasi perusahaan yang terancam di mata publik. Teori Image Restoration berkembang dari yang telah ada.

(2) Menjaga hubungan baik dengan MUSPIDA tetap membina hubungan dan mengikutsertakan MUSPIDA dalam setiap kegiatan yang diadakan Pertamina. Seperti event safety reading yang telah dikemukan 
diatas pihak POLRI di hadirkan juga sebagai narasumber untuk memberikan edukasi cara berkendara yang aman di jalan raya. Effendy (2003) beragamnya tujuan maupun kebutuhan saat berkomunikasi serta bagaimana upaya manusia mengikuti peraturan tertentu agar komunikasi tersebut berjalan dengan baik. Pada dasarnya setiap orang menginginkan komunikasi yang efektif. Komunikasi antar pribadi dikatakan efektif apabila antara komunikator dan komunikan terdapat persamaan dalam pengertian, sikap, sifat, nilai, kepercayaan, pendidikan, status sosial dan sebagainya. Komunikasi efektif dalam berkomunikasi adalah komunikasi yang bertanggung jawab. Efektif dalam berkomunikasi berguna untuk membangun hubungan dan kepercayaan dan rasa hormat .

Wentz (1998) komunikasi yang efektif menggunakan bahasa tertulis (verbal) dan komunikasi non verbal, termasuk keterampilan mendengarkan, penggunaan teknologi untuk mendukung komunikasi yang efisien dan memilih metode untuk mengevaluasi apakah komunikasi yang efektif. Pemilihan metode berkomunikasi menggunakan berbagai saluran komunikasi, cerita, formal dan komunikasi informal. Komunikasi yang efektif adalah penting bagi semua organisasi, seperti, sekolah, perusahaan dan sebagainya. Selain itu Daft (2008) menyarankan bahwa komunikasi yang efektif dapat dilakukan dengan mempengaruhi dan membujuk orang menuju visi dan inspirasi. Organisasi pertamina perlu banyak waktu untuk berkomunikasi dengan lembaga lain, konsumen melalui komunikasi tertulis, verbal dan nonverbal.

(3) Media monitoring dan Controling merupakan aktivitas rutin yang dilakukan untuk menganalisa berita yang beredar dan membina relations dengan media. Agar pihak unit Comuniction Relations dapat segera menepis setiap berita yang beleum terkonfirmasi pihak nya. Amalia et al. (2017) kerjasama antar media pertamina mampu meningkatkan hubungan dua rah yang saling bersinergi. Media memerlukan berita dan pertamina sebagai lembaga promosi memerlukan wadah sebagai informasi kepada konseumen dan lembaga mitra. Semua aktivitas tersebut direncanakan sebagai program kerja yang harus di realisasikan. Media monitoring sebagai filter pertama dalam menepis berita karena dari media monitoring dapat terdeteksi berita-berita yang cenderung negatif, arti negatif dan positif hanya masyarakat yang bisa menilai dari sebuah berita tersebut. Sehingga hal tersebut tidak bisa pihak Pertamina memaksa masyarakat untuk berpikir positif tetapi konfirmasi pihak Pertamina itu yang mengidentifikasikan bahwa berita itu apakah positif atau negatif. Negatifnya suatu berita yang belum di konfirmasi pihak Pertamina, selanjutnya akan di analisa lalu di hubungi pihak media yang telah memuat berita tersebut dan diajak komunikasi secara persuasif oleh unit communication relations dengan tujuan agak pihak Pertamina diberikan kesempatan untuk melakukan hak jawab dengan press realese.

\section{KESIMPULAN DAN SARAN}

\section{Kesimpulan}

Strategi public relations adalah suatu upaya dalam bidang komunikasi yang bertujuan untuk membina hubungan baik. Strategi public relations didalam suatu perusahaan tentunya memiliki tujuan yang tidak terlepas dari pada visi misi perusahaan. Strategi Coorporate image di Pertamina Marketing
Operation Region III terdapat dalam media monitoring. Fungsi nya sebagai menjembatani hubungan baik dengan MUSPIDA, sebagai media yang secara terencana dan berkesinambungan menyelenggarakan kegiatan-kegiatan (event) dan Tanggung Jawab Sosial (TJS) 


\section{Saran}

Strategi coorporate image dalam Unit kerja di Pertamina Marketing Operation Region III harus menjaga hubungan baik ke semua pihak yang berhubungan dengan Pertamina dan Pertamina harus selalu menjaga produk Pertamina dengan kualitas yang bagus dan kuantitas yang cukup tersedia untuk masyarakat sebagai konsumen. Kegiatankegiatan (Event) yang bertujuan membentuk Coorporate Image di rencanakan dan diselenggarakan dengan tepat sasaran dan berkesinambungan.

\section{DAFTAR PUSTAKA}

Amalia N, Ratnamulyani IA, Kusumadinata AA. 2017. Promosi personal selling surat kabar bogor today dalam menarik minat pemasang iklan. Jurnal Komunikatio 3 (1) : 9-20.

Anang RH. 2014. Modul Konsep Dasar Kehumasan. Palembang.

Afrizal. 2016. Metode Penelitian Kualitatif. Jakarta (ID) : Raja Grafindo Persada.

Aldhily R. 2017. 101 Amazing Public Relations Ideas. Yogyakarta (ID) : Quadrant.

Aydin S, Ozer G. 2005. The analysis of antecedents of customer loyalty in the Turkish mobiletelecommunication market. European Journal of Marketing 39 (7/8): 910-25.

Daft RL. 2007. Manajemen Edisi 6. Jakarta (ID) : PT. Salemba Empat.

Effendy OU. 2003. Ilmu, teori dan filsafat komunikasi. Bandung (ID) : Citra Aditya Bakti.

Fajri C. 2017. eran Humas Dalam Meningkatkan Loyalitas Stakeholder Universitas Ahmad Dahlan. [Skripsi]. Yogyakarta (ID) : Fakultas ilmu Sosial
Universitas Negeri Yogyakarta.

Kriyantono R. 2014. Teori Public Relations Perspektif Barat Dan Lokal: Aplikasi Penelitiandan Praktik. Jakarta (ID) : Kencana.

Littlejhon SW, Foss KA. 2017. Teori Komunikasi . Jakarta (ID) : Salemba Humanika,

Nova F. 2011. Crisis Public Relations Bagaimana PR Menangani Krisis Perusahaan. Jakarta (ID) : Raja Grafindo Persada.

Purwani DA. 2009. Hubungan Antara Corporate Image (CI) Dengan External Business Relations (EBR) (Studi kasus pada PT.Adiputro Yogyakarta). [Tesis]. Surakarta (ID) : Program studi Ilmu Komunikasi Program Pascasarjana Universitas Sebelas Maret Surakarta.

Ruslan R. 2016. Manajemen Public Relatins dan Media Komunikasi. Jakarta (ID) : PT. Raja Grafindo Persada.

Wentz CA. 1998. Safety, health, and environmental protection. Boston (US): McGraw-Hill. 